\title{
Attenuation of $P, S$ and Coda Waves in the NW-Himalayas, India
}

\author{
Imtiyaz A. Parvez, Preeti Yadav, K. Nagaraj \\ CSIR Centre for Mathematcial Modelling and Computer Simulation (C-MMACS) NAL, \\ Belur Campus, Bangalore, India \\ Email: parvez@cmmacs.ernet.in
}

Received August 5, 2011; revised September 19, 2011; accepted November 15, 2011

\begin{abstract}
The frequency-dependent characteristics of P- and S-wave attenuation in the upper crust of NW Himalayas have been estimated using local earthquakes for a frequency range of 1.5 to $18 \mathrm{~Hz}$. A total of 43 local events of magnitude 2.1 4.8, mostly from the vicinity of Main Boundary Thrust (MBT) and Main Central Thrust (MCT) have been used in the analysis. The extended coda normalization methods were applied to estimate the quality factors for P-waves $\left(Q_{P}\right)$ and S-waves $\left(Q_{S}\right)$ and the single back-scattering model has been used earlier (Kumar et al. [1]) to determine the quality factor for coda waves $\left(Q_{\mathrm{C}}\right)$. The observed quality factors $Q_{\mathrm{P}}$ and $Q_{\mathrm{S}}$ is strongly frequency dependent and the estimated average frequency dependent relation is given by $Q_{\mathrm{P}}=(97 \pm 3) f^{(1.06 \pm 0.06)}$ and $Q_{\mathrm{S}}=(127 \pm 6) f^{(0.96 \pm 0.06)}$ respectively for Pand S-waves. A comparison of $Q_{\mathrm{S}}$ estimated in this study and $Q_{\mathrm{C}}$ previously reported shows that $Q_{\mathrm{C}}>Q_{\mathrm{S}}$ for entire frequency range. This indicates the enrichment of coda waves and the importance of scattering attenuation to the attenuation of S-waves in the study region infested with faults and fractures. The ratio $Q_{S} / Q_{\mathrm{P}}$ is found to be greater than unity for the entire frequency range indicating that the body waves from source to station paths crossed a crustal volume with dry and rigid rocks. The frequency dependent relations developed in this study can be very useful to ground motion modeling which in turn is required in the seismic hazard assessment of the region.
\end{abstract}

Keywords: Attenuation; Quality Factor; Frequency Dependence; NW Himalayas

\section{Introduction}

In order to investigate the structure of the interior of the earth and to quantitatively predict the strong earthquake ground motion in engineering seismology, the information on seismic wave attenuation plays an important role. Especially, the information on high frequency wave attenuation in the lithosphere is of particular importance. Attenuation parameter $Q^{-1}$ is an important factor for understanding the physical mechanism of seismic wave atenuation in relation to the composition and physical condition of the earth's interior [2]. From the engineering point of view, attenuation of S-waves has been well studied in various regions in the world as compared with that of P-waves. Aki [3] first obtained frequency dependent $Q_{S}^{-1}$ in Kanto, Japan for the frequency range of $1.5-24 \mathrm{~Hz}$ by means of the coda-normalization method. Nevertheless, the information on $Q_{P}^{-1}$ is also indispensable for evaluating the strong vertical ground motion precisely in view of the earthquake-resistant design of recent huge constructions.

Attenuation of seismic waves with frequency strongly depends on the physical conditions of the underground crustal media and is caused by different factors like geo- metrical spreading, scattering, multipathing and anelasticity. The crustal value of attenuation, described as the inverse of the quality factor $\left(Q^{-1}\right)$, shows a close relation with seismic activity and is given Knopoff [4].

$$
Q^{-1}=-\Delta E / 2 \pi E
$$

where $\Delta E$ is the energy lost per cycle and $E$ is the total energy of a harmonic wave. $Q$ expresses the decay of wave amplitude during its propagation in the medium. It has been observed that at high frequency $(>1 \mathrm{~Hz}) Q$ increases with frequency [5] and can be represented by a power law,

$$
Q=Q_{0}\left(f / f_{0}\right)^{n}
$$

where $f$ is frequency, $Q_{0}$ is value of $Q$ at frequency $f_{0}(1$ $\mathrm{Hz}$ ) and $n$ is the frequency dependent coefficient to be determined from the observations.

The attenuation of seismic waves has been widely studied in several seismogenic zones using various approaches (e.g., [6-9]). It has been found that the attenuation for P-wave $\left(Q_{\mathrm{P}}^{-1}\right)$ is different from that of S-wave $\left(Q_{\mathrm{S}}^{-1}\right)$. The ratio $Q_{\mathrm{S}} / Q_{\mathrm{P}}$ also varies from one region to another [10]. The coda normalization method to estimate the 
frequency-dependent relation for $Q_{\mathrm{S}}$ is proposed by [3]. Reference [11] extended this method for simultaneous measurement of $Q_{P}$ and $Q_{S}$. Similarly, high frequency coda waves recorded during the occurrence of local earthquakes, which arrive at station after the arrival of all direct phases, are assumed to be the superposition of backscattered primary S-waves generated by the numerous heterogeneities distributed randomly in the earth's crust and upper mantle. These waves arrive at the station on different time intervals and form a coda. Therefore, the decay of these waves with time, in a seismogram, provides the average attenuation characteristics of the medium instead of the property of a single path connecting from a source to the station. As these waves are the result of numerous heterogeneities distributed randomly, they cannot be explained by any deterministic approach in which a number of parameters are required to describe a small portion of seismogram. However, they can be solved by applying the statistical method in which a small number of parameters is sufficient to describe the properties of coda waves. [6] and [7] are pioneers in this field and they proposed a single backscattering model to use the coda waves of local earthquakes for the estimation of quality factor $\left(Q_{C}\right)$ of coda waves in a region. Numerous studies have been carried out in different parts of the world to determine the seismic wave attenuation properties of the medium. These studies analyze the coda waves of local earthquakes for the estimation of $Q_{\mathrm{C}}$ values, using the single backscattering model (e.g., [1,12-17]). The main objective of this study is to understand the attenuation characteristics of the North-West Himalaya region using different parts of the seismograms including coda waves and body waves. For this purpose, the extended coda normalization method [11] has been used to estimate the frequency-dependent relationships for $Q_{\mathrm{P}}$ and $Q_{\mathrm{S}}$ in the NW Himalaya region and that is the first estimate of this kind for this region. The $Q_{\mathrm{C}}$ estimates for the NW Himalaya region have been previously obtained by [1] using the single back-scattering model of [7] and in the present study we integrate and compare the estimated $Q_{\mathrm{P}}$ and $Q_{\mathrm{S}}$ with $Q_{\mathrm{C}}$ obtained by [1].

\section{Tectonic Setup of the Region}

The Himalaya is the youngest mountains range and is developed by the continent-continent collision between Indian and Tibetan plate $[18,19]$. High levels of tectonic activity are due to the opposite convergence movements of north dipping Indian plate under Eurasian plate. The region is characterized by the presence of many tectonic features that includes Indian Tsangpo-Suture zone (ISZ), Main Central Thrust (MCT), Main Boundary Thrust (MBT) and Himalayan Frontal Thrust (HFT). The two thrusts exist through the entire length of the Himalaya.
The MBT separates the lesser Himalaya from the subHimalaya belt while MCT separates the high Himalaya from the lesser Himalaya. In the present study region, along with MCT, MBT and HFT the Jawalamukhi thrust (JMT), Drang thrust, Panjal thrust, Vakirata thrust, Sundernagar fault, Kistwar fault and Ropar fault are well known tectonic features. The tectonic movement of NW Himalayas and major discontinuities are shown in Figure 1. Reference [1] has explained in detail the tectonic setup of the region.

\section{Method of Analysis}

The coda normalization method [2] is based on the empirical observation that the coda spectral amplitude at lapse times greater than twice the S-wave travel time is proportional to the source spectral amplitude of the Swaves at distances of less than $100 \mathrm{~km}$. This implies that the coda spectral amplitude is not dependent to the hypo central distance and that the site and source terms which are common in coda and direct waves can be removed by the coda normalization method [3].

Reference [11] has extended the above method for the estimation of $Q$ under the assumption that the earthquakes within a magnitude range have the same spectral ratio of $\mathrm{P}$ - to $\mathrm{S}$-wave radiation within a narrow frequency range. This assumption holds well even if the spectral shapes of P- and S-waves are different (e.g., [10,20]). Therefore, we can write

$$
A_{\mathrm{c}}\left(f, t_{\mathrm{c}}\right) \propto S_{\mathrm{S}}(f) \propto S_{\mathrm{P}}(f)
$$

where, $S_{\mathrm{P}}(f)$ and $S_{\mathrm{S}}(f)$ are the source spectral amplitude of $\mathrm{P}$ - and S-waves. Using the above assumption, an equation for estimating $Q_{P}$ can be written as [33]:

$$
\begin{aligned}
& \ln \left[\frac{A_{\mathrm{P}}(f, r) r^{\gamma}}{A_{\mathrm{C}}\left(f, t_{c}\right)}\right]_{r \pm \Delta r}=-\frac{\pi f}{Q_{\mathrm{P}}(f) V_{\mathrm{P}}} r+\operatorname{const}(f) \\
& \ln \left[\frac{A_{\mathrm{S}}(f, r) r^{\gamma}}{A_{\mathrm{C}}\left(f, t_{\mathrm{c}}\right)}\right]_{r \pm \Delta r}=-\frac{\pi f}{Q_{\mathrm{S}}(f) V_{\mathrm{S}}} r+\operatorname{const}(f)
\end{aligned}
$$

where $A_{\mathrm{p}}(f, r)$ and $A_{\mathrm{S}}(f, r)$ are the direct P- and $\mathrm{S}$-waves maximum amplitudes at the hypocentral distance $r(\mathrm{~km})$, respectively. $V_{\mathrm{P}}$ and $V_{\mathrm{S}}$ are the average $\mathrm{P}$ - and S-wave velocities. The quality factor for P-wave can be obtained from the linear regression of

$\ln \left[\frac{A_{\mathrm{p}}(f, r) r^{\gamma}}{A_{\mathrm{C}}\left(f, t_{c}\right)}\right]_{r \pm \Delta r}$ versus $r$ by means of the least square method and same is used for S-waves.

\section{Data}

The study area covered comprises of three seismic stations Pathankot (PTK), Hoshiarpur (HOS) and Amritsar 


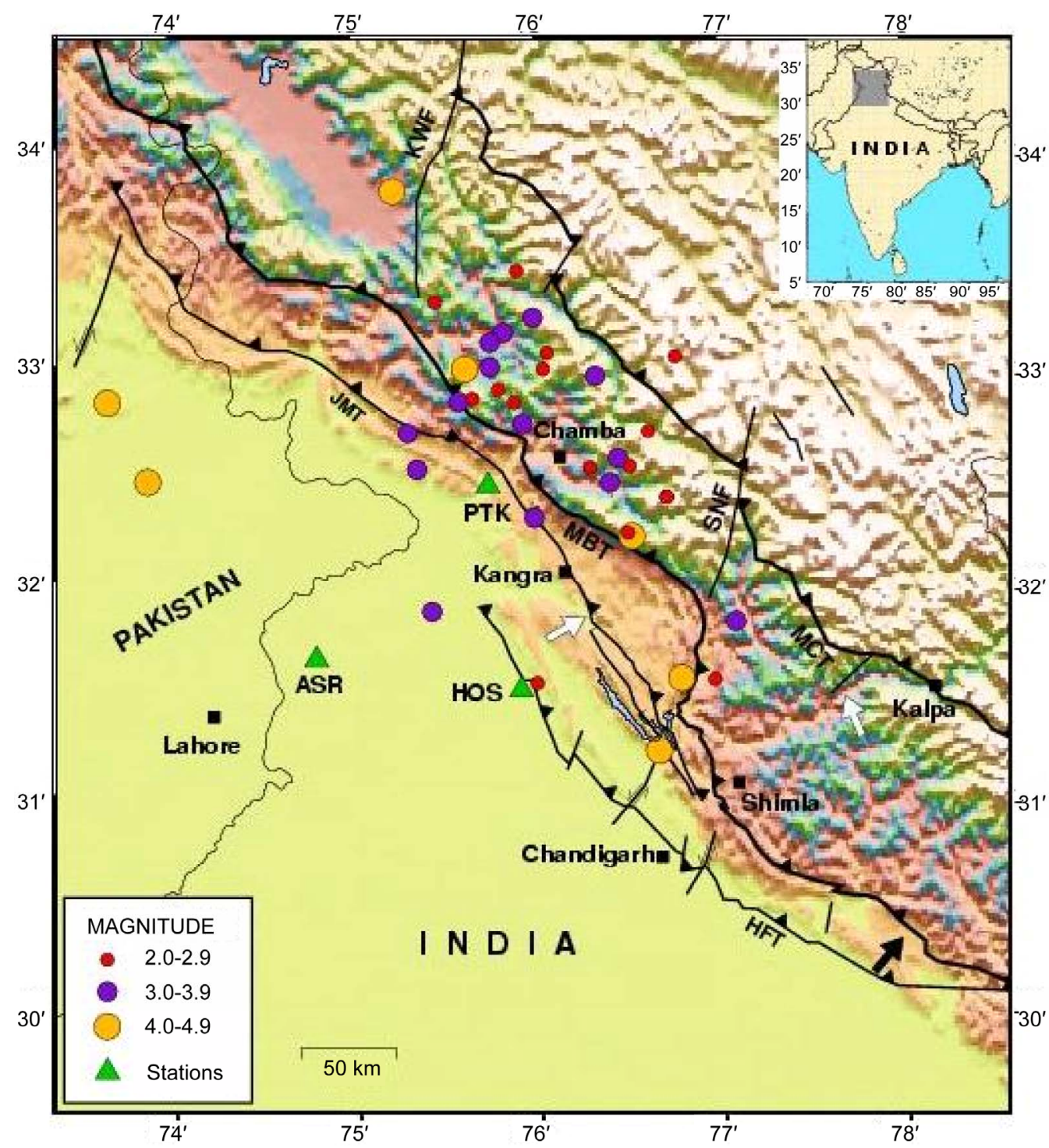

Figure 1. General Seismotectonic and topographical map of NW Himalayas and adjoining area. MCT: Main Central Thrust; MBT: Main Boundary Thrust; HFT: Himalayan Frontal Thrust; JMT: Jawalamukhi Thrust; KWF: Kisatwar Fault; SNF: Sundarnager Fault; earthquake epicentres are plotted by circles, triangles represent the recording stations (PTK: Pathankot; HOS: Hoshiarpur; ASR: Amritsar) and cities are shown by squares.

(ASR) in NW Himalaya region (Figure 1). The first seismic station, PTK is on the top of the Siwalik Hills; the second one, HOS is at Siwalik foothills; while third one, ASR station is located on the Gangetic plain. The station PTK is situated on hard bedrock in the vicinity of high tectonic and seismic activity at high altitude. The station HOS is situated at alluvium near recent tectonic and moderate seismic activity, and the station ASR is on a thick alluvium of the Gangetic plain away from tectonic and seismic activities. All the stations were equipped with portable high quality three component short-period $(1 \mathrm{~Hz}$ natural frequency) L4-3D seismometers of Mark products (USA) and high dynamic range 24 bit recording apparatus of REFTEK (USA). The instruments were set- up to digitize the signal at 100 sps and an antiallising filter was applied to get the flat velocity spectrum between 1 and $40 \mathrm{~Hz}$. The digital events data utilized for $Q$ calculation were recorded during 1997-1999 at the regional seismograph network of three seismic stations by Earthquake Research Centre, Guru Nanak Dev University, Amritsar. During the given period, more than 300 seismic events were recorded from different epicentral ranges. Out of these, 36 local events were used by [1] for coda $Q$ calculation and the same has been used in this study for estimating $Q_{\mathrm{P}}$ and $Q_{\mathrm{S}}$.

The detailed epicentral information of seismic events is listed in Table 1, which indicates that the maximum events are recorded at PTK station while minimum events 
Table 1. Earthquake data used for $Q_{\mathrm{P}}$ and $Q_{\mathrm{s}}$ calculation.

\begin{tabular}{|c|c|c|c|c|c|c|c|}
\hline $\begin{array}{l}\text { Sr. } \\
\text { No. }\end{array}$ & $\begin{array}{c}\text { Date } \\
(\mathrm{dd} / \mathrm{mm} / \mathrm{yy})\end{array}$ & $\begin{array}{l}\text { O.Time } \\
\text { (hh:mm:ss) }\end{array}$ & $\begin{array}{l}\text { Latitude } \\
\left({ }^{\circ} \mathrm{N}\right)\end{array}$ & $\begin{array}{c}\text { Longitude } \\
\left({ }^{\circ} \mathrm{E}\right)\end{array}$ & $\begin{array}{c}\Delta \\
(\mathrm{km})\end{array}$ & $\begin{array}{c}\text { Depth } \\
(\mathrm{km})\end{array}$ & M \\
\hline \multicolumn{8}{|c|}{ Station: Pathankot } \\
\hline 1 & $23 / 12 / 97$ & 04:15:04.90 & 33.805 & 75.234 & 161 & 33.0 & 4.0 \\
\hline 2 & $25 / 04 / 98$ & $18: 15: 50.80$ & 31.533 & 76.028 & 108 & 30.0 & 2.3 \\
\hline 3 & $18 / 05 / 98$ & $12: 29: 31.80$ & 33.157 & 75.839 & 102 & 65.0 & 3.5 \\
\hline 4 & 01/07/98 & $22: 50: 51.40$ & 32.691 & 75.318 & 53 & 19.5 & 3.5 \\
\hline 5 & 05/07/98 & $22: 33: 36.70$ & 32.852 & 75.675 & 55 & 10.0 & 2.4 \\
\hline 6 & $05 / 07 / 98$ & $23: 04: 21.80$ & 32.837 & 75.596 & 47 & 12.0 & 3.0 \\
\hline 7 & $06 / 07 / 98$ & $10: 24: 08.80$ & 32.987 & 75.629 & 102 & 82.5 & 4.2 \\
\hline 8 & $31 / 07 / 98$ & $02: 16: 14.50$ & 32.522 & 75.372 & 37 & 6.0 & 3.6 \\
\hline 9 & $17 / 08 / 98$ & $17: 55: 00.80$ & 33.223 & 76.001 & 95 & 33.0 & 3.4 \\
\hline 10 & $25 / 08 / 98$ & 11:48:04.90 & 32.543 & 76.533 & 75 & 15.0 & 2.6 \\
\hline 11 & $02 / 09 / 98$ & 01:02:26.10 & 32.957 & 76.342 & 79 & 5.0 & 3.0 \\
\hline 12 & 28/09/98 & $00: 21: 02.60$ & 32.737 & 75.947 & 40 & 15.0 & 3.1 \\
\hline 13 & 28/09/98 & 21:17:01.00 & 31.551 & 76.995 & 154 & 22.0 & 2.2 \\
\hline 14 & $17 / 10 / 98$ & 09:24:45.00 & 32.217 & 76.545 & 85 & 33.0 & 4.5 \\
\hline 15 & $06 / 11 / 98$ & $14: 29: 34.50$ & 32.299 & 76.010 & 44 & 34.0 & 3.8 \\
\hline 16 & $11 / 01 / 99$ & 01:30:26.10 & 31.820 & 77.115 & 146 & 5.0 & 3.5 \\
\hline 17 & $16 / 01 / 99$ & 03:07:46.80 & 32.987 & 76.058 & 66 & 5.0 & 2.7 \\
\hline 18 & $15 / 02 / 99$ & $00: 14: 52.00$ & 32.232 & 76.523 & 76 & 4.0 & 2.7 \\
\hline 19 & $21 / 02 / 99$ & $15: 14: 56.50$ & 32.833 & 75.898 & 46 & 10.0 & 2.1 \\
\hline 20 & $15 / 03 / 99$ & $21: 56: 37.50$ & 33.062 & 76.078 & 75 & 5.0 & 2.5 \\
\hline 21 & 16/03/99 & $19: 16: 19.20$ & 32.396 & 76.732 & 93 & 15.0 & 2.3 \\
\hline 22 & $22 / 03 / 99$ & 20:31:17.70 & 32.894 & 75.813 & 50 & 5.0 & 2.2 \\
\hline 23 & 27/03/99 & $11: 49: 31.40$ & 32.462 & 76.422 & 63 & 10.0 & 3.5 \\
\hline 24 & $22 / 04 / 99$ & 05:22:04.80 & 32.996 & 75.768 & 61 & 7.0 & 3.2 \\
\hline 25 & 07/05/99 & $14: 44: 57.40$ & 31.861 & 75.455 & 70 & 33.0 & 3.0 \\
\hline 26 & 08/05/99 & $20: 59: 17.40$ & 33.442 & 75.912 & 112 & 15.0 & 2.7 \\
\hline 27 & $12 / 07 / 99$ & $21: 45: 59.40$ & 33.110 & 75.768 & 102 & 72.0 & 3.7 \\
\hline 28 & 27/07/99 & 20:19:09.70 & 32.577 & 76.466 & 68 & 10.0 & 3.2 \\
\hline 29 & 28/07/99 & $10: 42: 52.70$ & 32.533 & 76.313 & 53 & 10.0 & 2.5 \\
\hline 30 & $30 / 07 / 99$ & $18: 18: 25.20$ & 32.704 & 76.633 & 88 & 15.0 & 2.5 \\
\hline 31 & $31 / 07 / 99$ & $13: 02: 25.80$ & 33.046 & 76.777 & 116 & 15.0 & 2.2 \\
\hline \multicolumn{8}{|c|}{ Station: Amritsar } \\
\hline 32 & $29 / 07 / 97$ & $09: 43: 35.80$ & 32.831 & 73.680 & 171 & 10.0 & 4.8 \\
\hline 33 & $29 / 07 / 97$ & 18:00:18.20 & 31.554 & 76.817 & 189 & 33.0 & 4.7 \\
\hline 34 & $13 / 08 / 97$ & $23: 10: 15.10$ & 31.211 & 76.694 & 184 & 33.0 & 4.2 \\
\hline 35 & $21 / 02 / 98$ & 19:08:04.30 & 33.292 & 75.466 & 193 & 15.0 & 2.6 \\
\hline 36 & $24 / 03 / 98$ & $04: 25: 42.90$ & 32.462 & 73.901 & 126 & 42.5 & 4.0 \\
\hline 37 & 01/07/98 & $22: 50: 51.40$ & 32.691 & 75.318 & 126 & 19.5 & 3.5 \\
\hline 38 & 05/07/98 & 23:04:21.80 & 32.837 & 75.596 & 152 & 12.0 & 3.0 \\
\hline 39 & $28 / 09 / 98$ & 21:17:01.10 & 31.551 & 76.995 & 202 & 30.0 & 2.2 \\
\hline 40 & $17 / 10 / 98$ & 09:24:45.00 & 32.217 & 76.545 & 175 & 33.0 & 4.5 \\
\hline \multicolumn{8}{|c|}{ Station: Hoshiarpur } \\
\hline 41 & 05/07/98 & 23:04:30.00 & 32.837 & 75.600 & 115 & 12.0 & 3.0 \\
\hline 42 & $17 / 10 / 98$ & 09:24:45.00 & 32.217 & 76.550 & 98.2 & 4.5 & 4.5 \\
\hline 43 & $06 / 11 / 98$ & $14: 29: 34.50$ & 32.299 & 76.010 & 95.4 & 34.0 & 3.8 \\
\hline
\end{tabular}


at HOS station. All the 31 events of PTK station used here are from $25 \leq \mathrm{R} \leq 165 \mathrm{~km}$ of epicentral distance, all nine events of ASR station used are from $100 \leq \mathrm{R} \leq 205$ $\mathrm{km}$ of epicentral distance and in case of HOS station total three events taken are from $50 \leq \mathrm{R} \leq 115 \mathrm{~km}$ epicenter range. Most of the seismic events are located between MBT and MCT bounded by two other transverse faults as the Sundernagar fault to the east and of same trend the Kistwar fault to the west. This region is very close to the PTK station in the northeast direction.

\section{Results and Discussion}

The seismograms have been filtered using Butterworth band pass filter with six frequency pass bands of $0.5-1.5$ $\mathrm{Hz}, 1-3 \mathrm{~Hz}, 2-5 \mathrm{~Hz}, 5-10 \mathrm{~Hz}, 10-15 \mathrm{~Hz}$ and $12-24$ $\mathrm{Hz}$. On the filtered seismograms, maximum amplitudes of direct P- and S-waves were measured from vertical and horizontal component respectively. The coda spectral amplitude, $A_{\mathrm{c}}\left(f, t_{\mathrm{c}}\right)$, has been measured for each frequency band by choosing to be longer than twice the Swave travel time. The average velocities of $6.1 \mathrm{~km} / \mathrm{sec}$ and $3.5 \mathrm{~km} / \mathrm{sec}$ for $\mathrm{P}$ - and $\mathrm{S}$-waves, respectively, have been used in the present study [1]. We also assume the geometrical spreading is proportional to $r^{-1}$. The plots of the quantity $\ln \left(\left(A_{\mathrm{p}} / A_{\mathrm{c}}\right) r\right)$ and $\ln \left(\left(A_{\mathrm{s}} / A_{\mathrm{c}}\right) r\right)$ versus $r$ along with the least square fitted lines for the station PTK are shown in Figure 2. The corresponding plots of the other two stations ASR and HOS are shown in Figures $\mathbf{3}$ and $\mathbf{4}$ respectively. The slopes of the best fitted lines are used to estimate $Q_{\mathrm{P}}$ and $Q_{\mathrm{S}}$ using the Equations (4) and (5) respectively for six different frequency bands. The mean values of $Q_{P}$ and $Q_{S}$, thus, obtained at different frequency bands and their average values for the three stations, are given in Table 2. We note that the estimated $Q$ values increase with the increase in frequency.

The value of $Q_{P}$ for PTK Station varies from 94 at (0.5 - 1.5) $\mathrm{Hz}$ to 1893 at $\left(12\right.$ - 24) $\mathrm{Hz}$, for ASR Station $Q_{\mathrm{P}}$ varies from 68 at $(0.5-1.5) \mathrm{Hz}$ to 1783 at $(12-24) \mathrm{Hz}$ and for HOS Station it varies from 71 at $(0.5-1.5) \mathrm{Hz}$ to 1656 at $\left(12\right.$ - 24) Hz. Similarly, the value of $Q_{S}$ for PTK Station varies from 168 at $(0.5-1.5) \mathrm{Hz}$ to 2694 at (12 24) $\mathrm{Hz}$, for ASR Station, the range is from 122 at (0.5 1.5) $\mathrm{Hz}$ to 2155 at $(12-24) \mathrm{Hz}$ and for HOS Station, it varies from 115 at $(0.5-1.5) \mathrm{Hz}$ to 2245 at $(12-24) \mathrm{Hz}$. The average value for the region is also estimated and it varies from 78 at $(0.5-1.5) \mathrm{Hz}$ to 1777 at $(12-24) \mathrm{Hz}$ for $Q_{\mathrm{P}}$ and for $Q_{\mathrm{S}}$, the values are 135 at $(0.5-1.5) \mathrm{Hz}$ to 2365 at (12 - 24) Hz.

We find a clear frequency dependency of $Q_{\mathrm{P}}$ and $Q_{\mathrm{S}}$ as they increase with frequency and that indicates the frequency-dependent nature of $Q$ estimates in the region.

Their frequency dependencies indicate that the attenuation of $\mathrm{P}$ - and $\mathrm{S}$-waves at high frequencies is less pronounced than at lower frequencies. This is a characteristic of tectonically active zones with complex structure. In order to estimate the frequency-dependent relations for $Q$, the power law $Q=Q_{0} f^{n}$ is fitted to the estimated $Q$ values for each station. We have plotted $\log Q_{\mathrm{P}}$ and $\log Q_{\mathrm{S}}$ with the $\log$ of frequency to estimate the frequency-dependent relationships as shown in Figure 5. The frequency-dependent relations thus obtained for all the three stations, along with the average, are given in Table 3. The average frequency-dependent relations for the region are $Q_{\mathrm{P}}=(97 \pm 3) f^{(1.06 \pm 0.06)}$ and $Q_{\mathrm{S}}=(127 \pm 6) f$ $(0.96 \pm 0.06)$

We have estimated $Q_{\mathrm{C}}$ earlier for NW-Himalayas [1]

Table 2. $Q_{\mathrm{P}}$ and $Q_{\mathrm{S}}$ values obtained for the three stations and their average values for six different frequency bands.

\begin{tabular}{ccccccccccc}
\hline \multirow{2}{*}{ Sl. No. } & $\begin{array}{c}\text { Freq. band } \\
\text { (Hz) }\end{array}$ & \multicolumn{2}{c}{ ASR } & \multicolumn{2}{c}{ HOS } & \multicolumn{3}{c}{ PTK } & \multicolumn{3}{c}{ Average } \\
\cline { 2 - 11 }$y$ & $\boldsymbol{Q}_{\mathbf{P}}$ & $\boldsymbol{Q}_{\mathbf{S}}$ & $\boldsymbol{Q}_{\mathbf{P}}$ & $\boldsymbol{Q}_{\mathbf{S}}$ & $\boldsymbol{Q}_{\mathbf{P}}$ & $\boldsymbol{Q}_{\mathbf{S}}$ & $\boldsymbol{Q}_{\mathbf{P}}$ & $\boldsymbol{Q}_{\mathbf{S}}$ \\
\hline 1 & $0.5-1.5$ & 68 & 122 & 71 & 115 & 94 & 168 & 78 & 135 \\
2 & $1-3$ & 132 & 409 & 126 & 245 & 261 & 288 & 173 & 314 \\
3 & $2-5$ & 323 & 551 & 314 & 495 & 653 & 919 & 430 & 655 \\
4 & $5-10$ & 647 & 1124 & 712 & 998 & 884 & 1421 & 748 & 1181 \\
5 & $10-15$ & 1075 & 1764 & 1013 & 1492 & 1508 & 1727 & 1199 & 1661 \\
6 & $12-24$ & 1783 & 2155 & 1656 & 2245 & 1893 & 2694 & 1777 & 2365 \\
\hline
\end{tabular}

Table 3. Frequency-dependent relationships of $Q_{P}$ and $Q_{S}$ obtained for the three stations and overall average value for the region.

\begin{tabular}{ccccc}
\hline \multicolumn{5}{c}{ Frequency-dependent relationships for three stations } \\
\hline Sl. No. & Station Code & Relation for P wave & Relation for S wave & $Q_{\mathrm{S}} / Q_{\mathrm{P}}$ ratio \\
\hline 1 & ASR & $Q_{P}=(98 \pm 4) f^{(1.11 \pm 0.04)}$ & $Q_{S}=(119 \pm 7) f^{(0.94 \pm 0.07)}$ & 1.21 \\
2 & HOS & $Q_{P}=(85 \pm 3) f^{(1.1 \pm 0.06)}$ & $Q_{S}=(122 \pm 3) f^{(1.01 \pm 0.03)}$ & 1.43 \\
3 & PTK & $Q_{P}=(103 \pm 8) f^{(0.99 \pm 0.09)}$ & $Q_{S}=(139 \pm 13) f^{(0.95 \pm 0.09)}$ & 1.35 \\
4 & Average & $Q_{P}=(97 \pm 3) f^{(1.06 \pm 0.06)}$ & $Q_{S}=(127 \pm 6) f^{(0.96 \pm 0.06)}$ & 1.31 \\
\hline
\end{tabular}



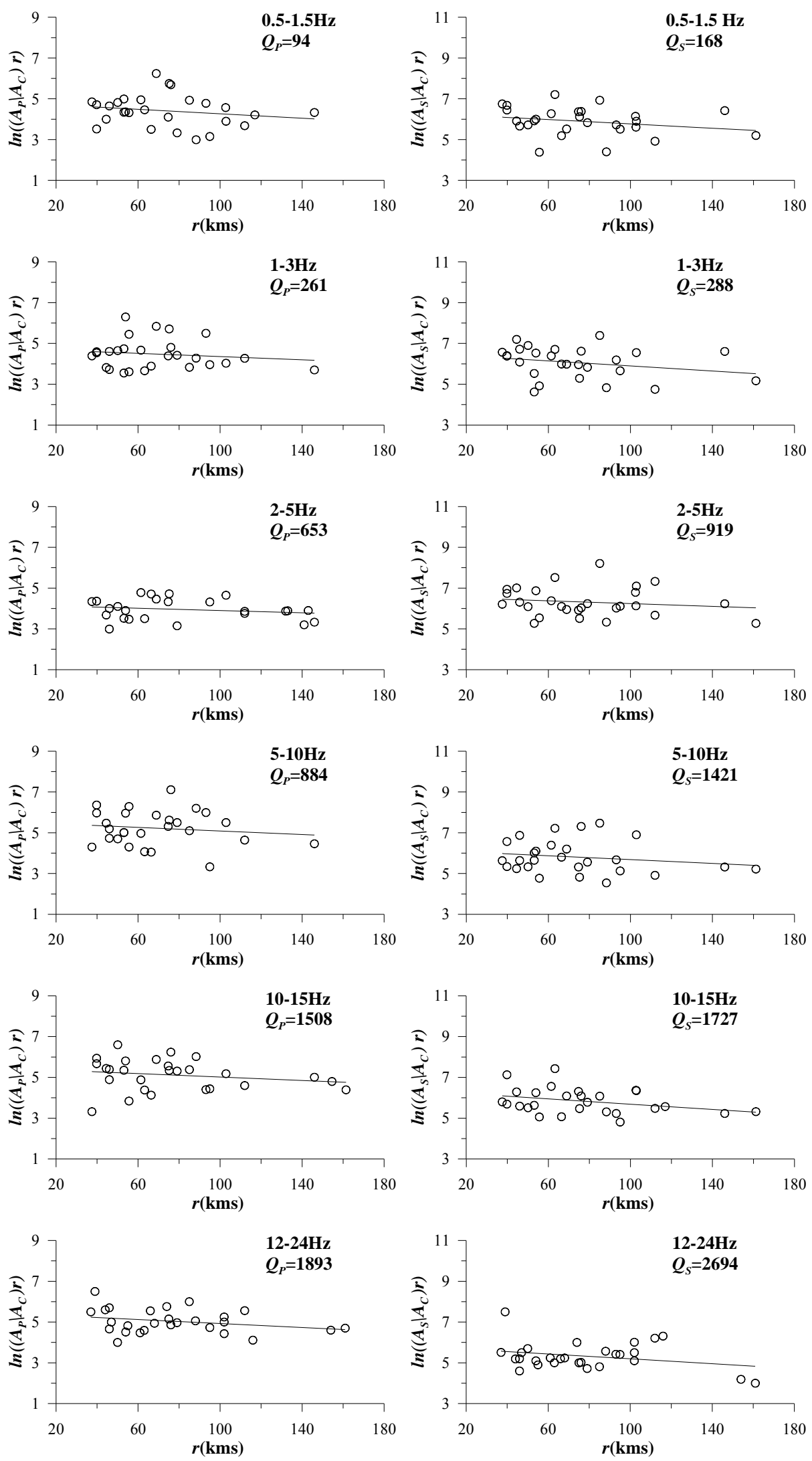

Figure 2. Plots of coda normalized peak amplitude decay of P- and S-waves with hypocentral distance for the six frequency bands along with least-square best fitted line for PTK station. 

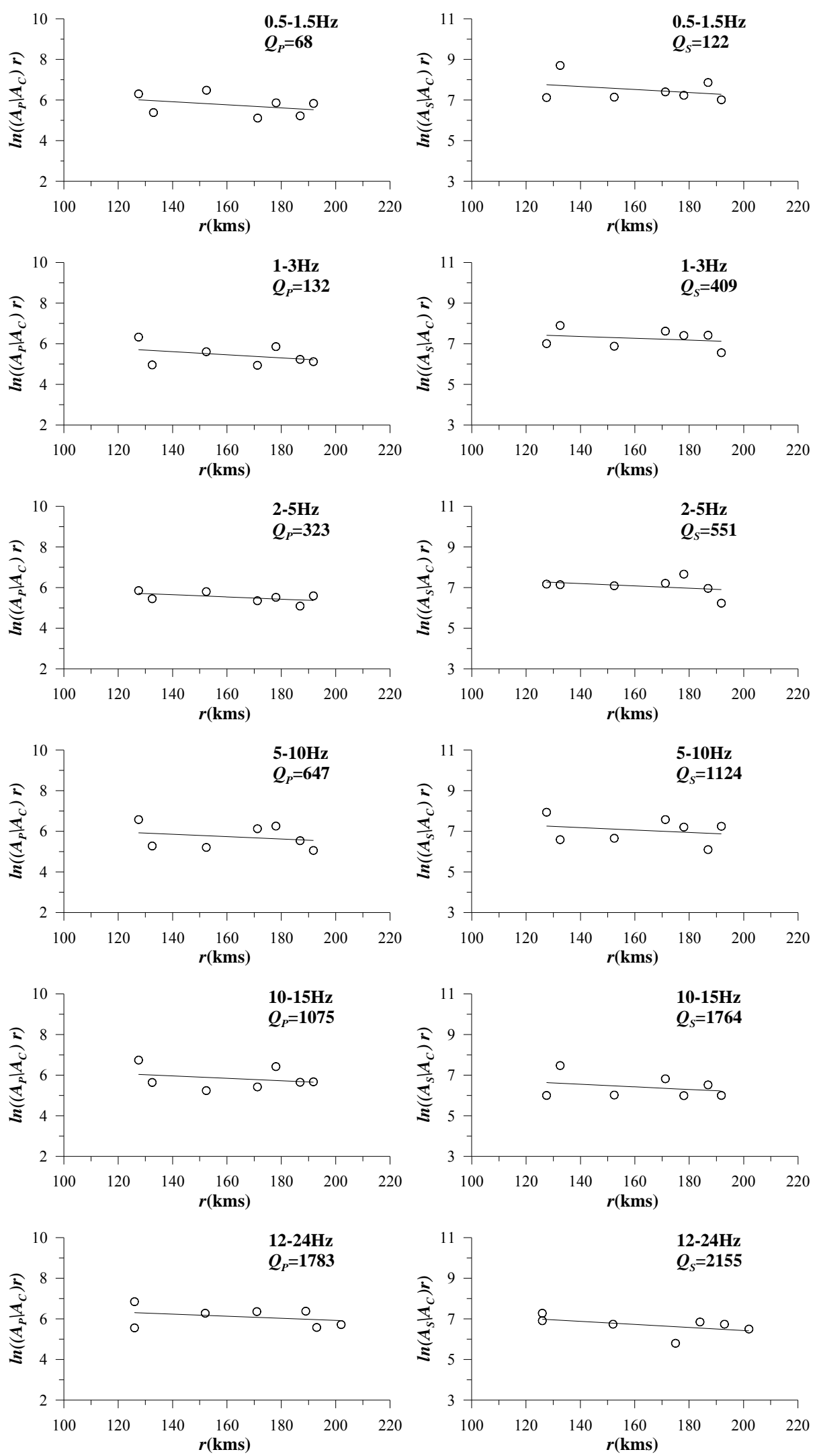

Figure 3. Plots of coda normalized peak amplitude decay of P- and S-waves with hypocentral distance for the six frequency bands along with least-square best fitted line for ASR station. 

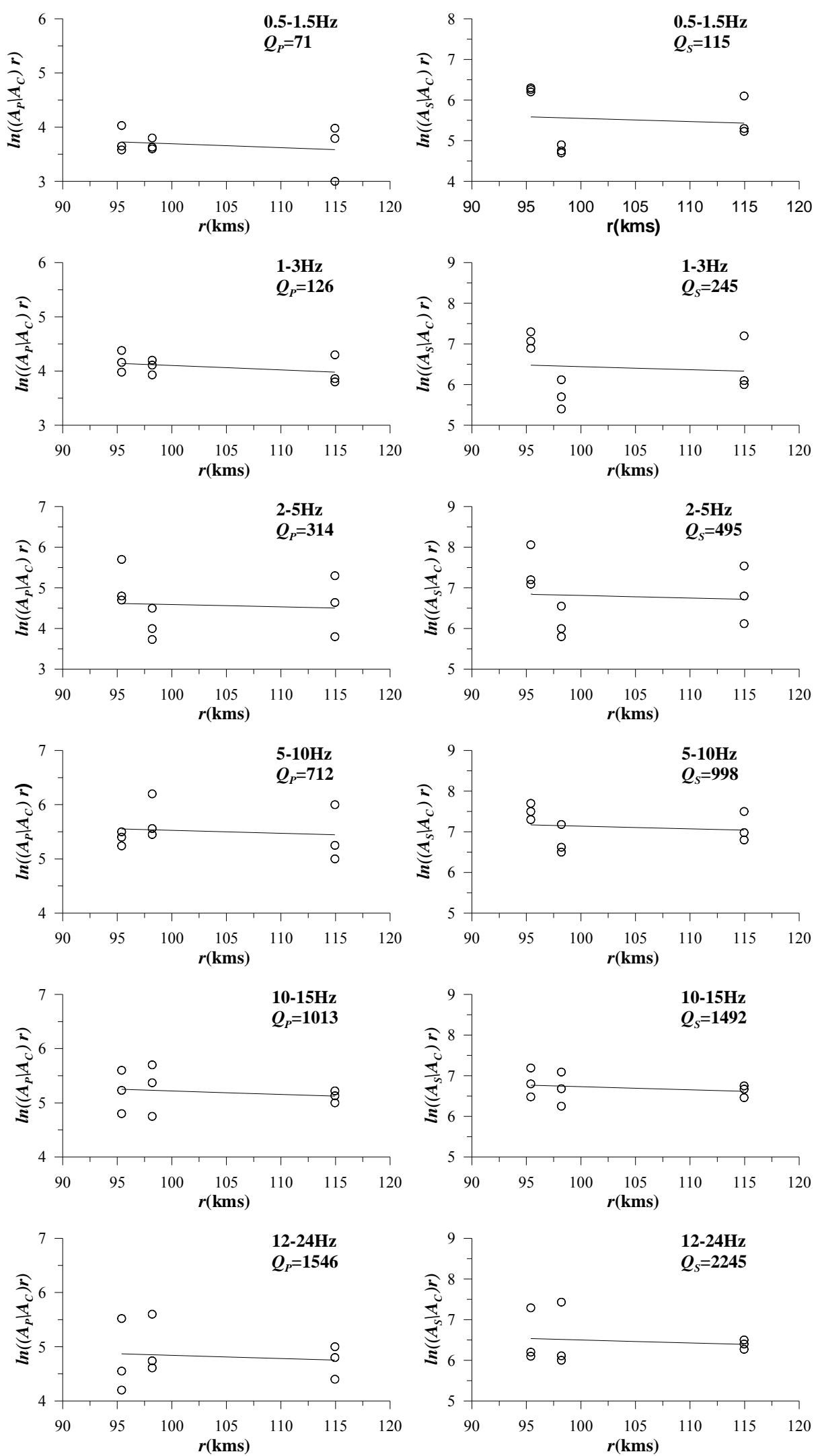

Figure 4. Plots of coda normalized peak amplitude decay of P- and S-waves with hypocentral distance for the six frequency bands along with least-square best fitted line for HOS station. 

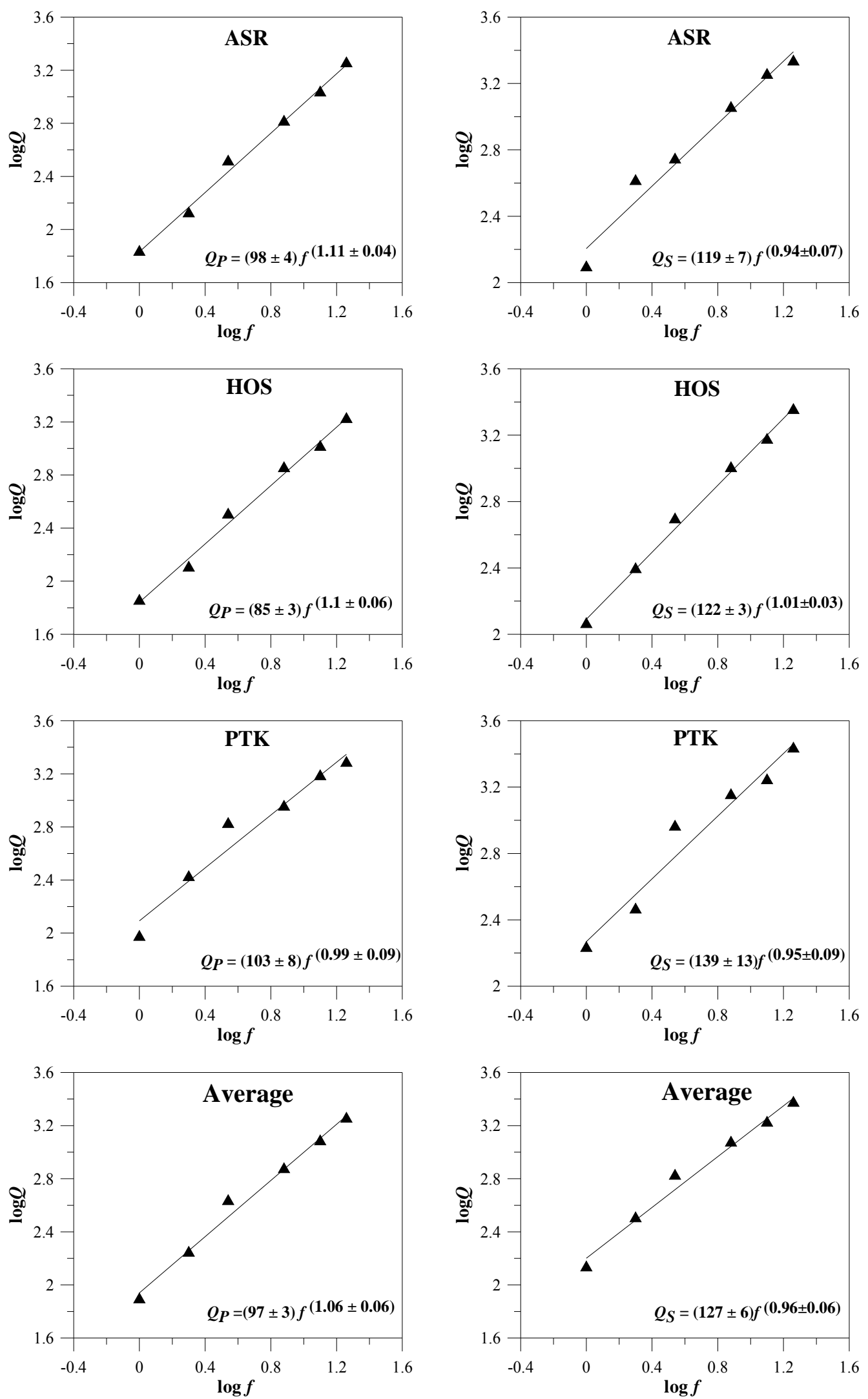

Figure 5. Frequency-dependent relationships for the three stations ASR, HOS and PTK respectively, along with average of all the three stations. 
using the back-scattering model [7] and we have found $Q_{\mathrm{C}}=158 f^{1.05}$ for the NW Himalaya region. It has been found by [6] and [7] that the coda waves are determined by $\mathrm{S}$ to S-backscattered waves and have common amplitude decay (e.g., Rautian et al., [10]). On the other hand Zeng et al. model [21] predicts that the effects of intrinsic and scattering attenuation combine in a manner such that $Q_{\mathrm{C}}$ should be more than $Q_{\mathrm{S}}$.

We compared $Q_{\mathrm{C}}, Q_{\mathrm{P}}$ and $Q_{\mathrm{S}}$ for this region and the estimated average $Q$ values as a function of frequency is shown in Figure 6. One can see from this figure that $Q_{\mathrm{C}}$ is always greater than $Q_{S}$ and $Q_{P}$ for all the frequency ranges that indicate possible high frequency coda enrichment. This may also be due to scattering attenuation in the upper lithosphere which is highly heterogeneous. The high frequency coda enrichment has also been reported from other regions (e.g., [22,23]). Such observation may be further investigated using the multiple scattering models [24].

Figure 6 also shows that the ratio $Q_{S} / Q_{P}$ is always greater than 1 for entire frequency range and is closed to 1 at high frequency. It has been found from the laboratory measurements that $Q_{\mathrm{S}} / Q_{\mathrm{P}}$ ratio is less than unity in fluid saturated rock matrices and larger than unity in dry rocks (e.g., [25-27]). Vassiliou et al., [28] also found that the $Q_{\mathrm{S}} / Q_{\mathrm{P}}$ ratio to be unity for air dry rocks and less than unity for fully saturated rocks. The study of Johnston et al., [29] also indicates that at surface pressure most dry rocks have $Q_{\mathrm{S}} / Q_{\mathrm{P}}>1$. Our result on $Q_{\mathrm{S}} / Q_{\mathrm{P}}$ ratio is in the range of $1.21-1.43$ (Table 3) and is well in agreement with the results obtained by the laboratory measurement and other experimental results mentioned above. If we see $Q_{\mathrm{S}} / Q_{\mathrm{P}}$ ratio for individual stations, Amritsar (ASR) has the least 1.21 compared to the other two stations HOS and PTK closed to Himalayas and Himalayan foothills. We found the similar situation with $Q_{\mathrm{C}}$ values also [1]. Such difference in attenuation properties is due to real crustal differences and may be the scatters in the region have different patterns. The ratio $Q_{S} / Q_{P}$ as well as the frequency dependence of quality factors estimated in this study indicates that the scattering is an important factor contributing to the attenuation of body waves in the region. The $Q_{S} / Q_{P}$ ratio having values larger than unity also indicates that the body waves from source to station paths crossed a crustal volume having dry and rigid rocks.

The $Q_{\mathrm{P}}$ and $Q_{\mathrm{S}}$ values obtained in the present study have been compared with those estimated for other tectonic and seismically active different regions of the world in Figures 7(a) \& (b). We observe from the Figure 7(a) that the rate of increase of $Q(f)$ for P-wave in the NW Himalaya region is similar with those of other regions like the Kachchh, Saurastra and Mainland region of Gujarat, India. They also compare very well with other re-

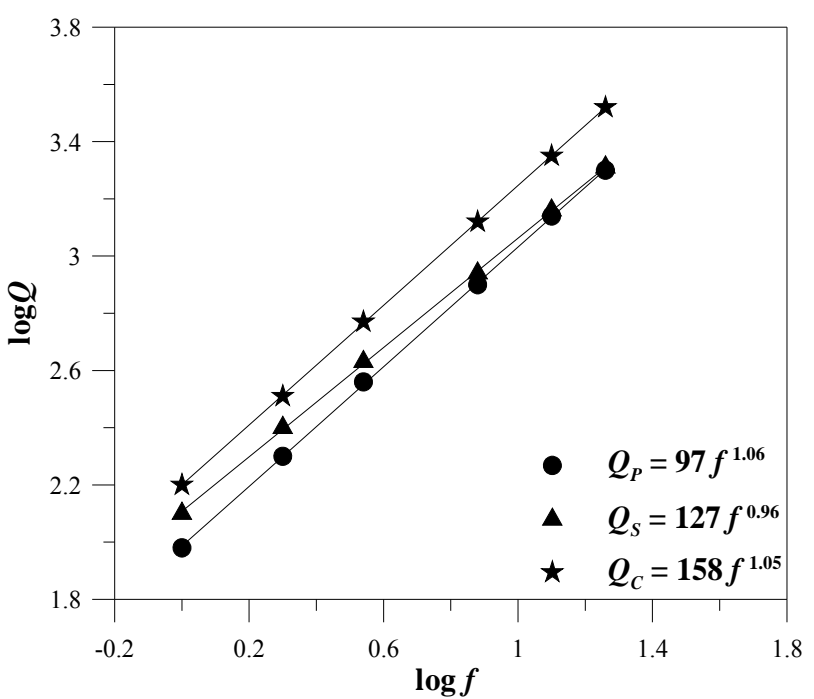

Figure 6. Estimated average $Q$ values as a function of frequency for $P, S$, and coda waves, and the corresponding fitting of power law.

gions like Baltic Shield and South Eastern Korea. However, they differ in absolute values from the regions like Koyna, Chamoli, Kanto region of Japan and Central South Korea. A similar comparison is shown in Figure 7(b) for $Q_{\mathrm{S}}$ of NW-Himalaya region with other regions of the world and this also show the similar trend of the rate of increase of $Q(f)$ for S-wave. If we compare with other regions of the world, except for the Saurastra, all the other regions are very well compared with the present study. The $Q_{\mathrm{S}}$ of Saurastra region at low frequency is well comparable, however at high frequency it is high compared to the other region. Such variation may also be due to different geology and tectonics, as most of the Saurastra region is covered by Deccan basalt which is compact and rigid and that is more sensitive to frequency.

\section{Conclusions}

This study is an attempt to understand the attenuation of P-, S- and Coda-waves in the NW-Himalayas of the India using the different parts of the seismograms. The frequency-dependent estimates of body waves $\left(Q_{P}\right.$ and $\left.Q s\right)$ have been obtained using the extended coda normalizetion method, and the single back-scattering model has been used to determine the relation for coda waves. The obtained relations are $Q_{\mathrm{P}}=(97 \pm 3) f^{(1.06 \pm 0.06)}$ and $Q_{\mathrm{S}}=$ $(127 \pm 6) f^{(0.96 \pm 0.06)}$ and show strong dependency on frequency. The frequency dependent $Q_{\mathrm{P}}, Q_{\mathrm{S}}$ and $Q_{\mathrm{C}}$ indicates that the seismic energy of high frequency waves is attenuated more in the upper lithosphere than in the lower lithosphere. We also found that $Q_{\mathrm{P}}$ and $Q_{\mathrm{S}}$ of NW Himalaya is comparable to the other seismic active region of the world like Kachchh, Saurastra and Mainland region of Gujarat, India, Baltic Shield and South Eastern 


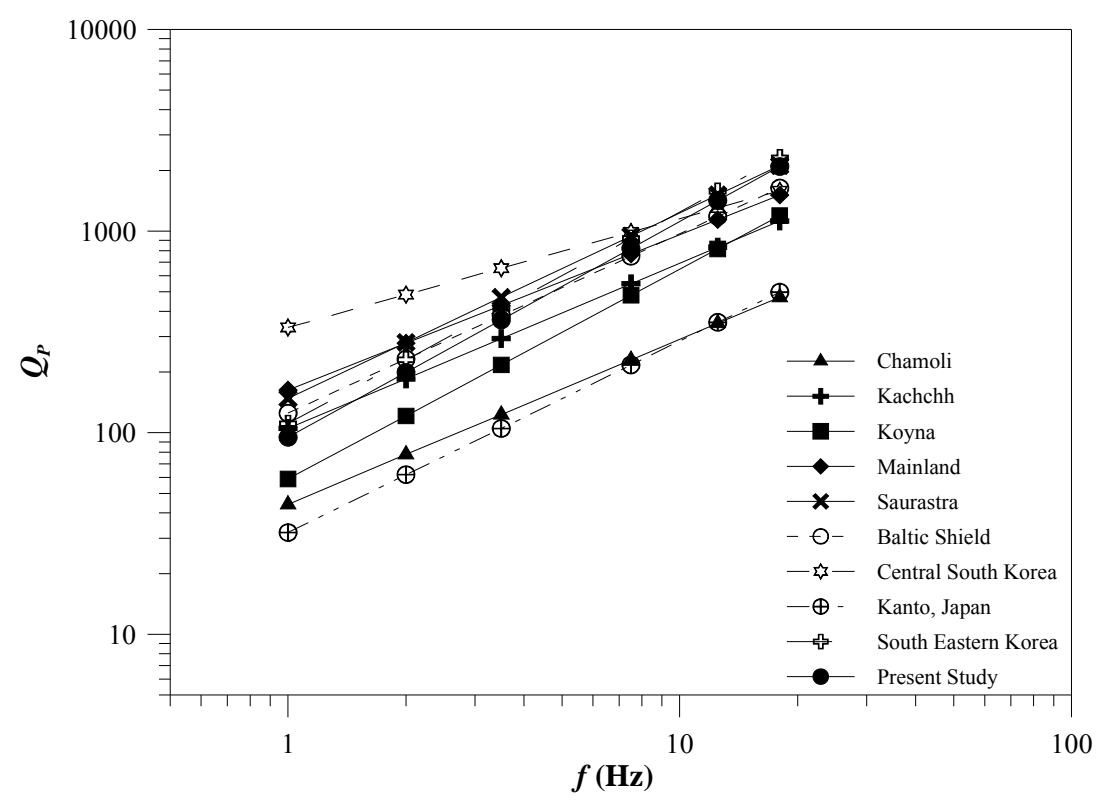

(a)

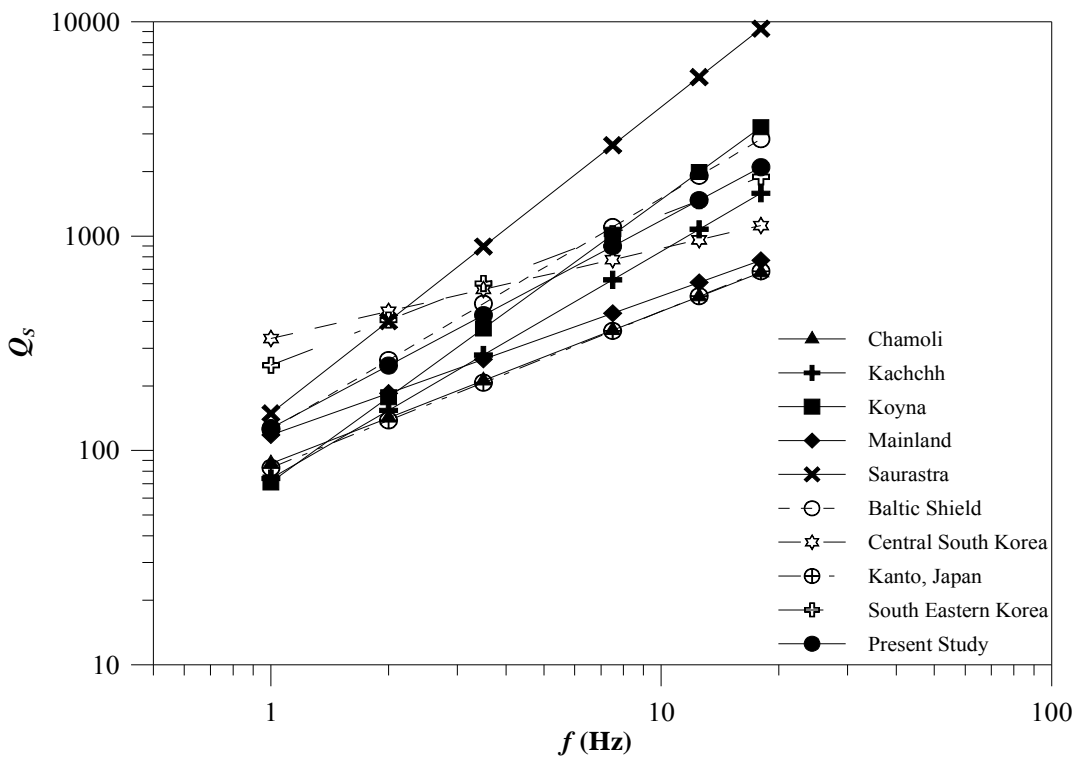

(b)

Figure 7. (a) Comparison of $Q(f)$ for P-waves of the NW Himalaya region obtained in this study $\left(Q(f)=97 f^{1.06}\right)$ with those of other regions of the world (dashed lines) and India (solid lines). Line 1: Chamoli, Himalaya, $Q(f)=44 f^{0.82}[30]$; Line 2: Kachchh region, Gujarat, $Q(f)=105 f^{0.82}$ [31]; Line 3: Koyna region, $Q(f)=59 f^{1.04}$ [32]; Line 4: Mainland region, Gujarat, $Q(f)=163 f^{0.77}$, [31]; Line 5: Saurastra region, Gujarat, $Q(f)=148 f^{0.92}$, [31]; Line 6: Baltic Shield, $Q(f)=125 f^{0.89}$, [33]; Line 7: Central South Korea, $Q(f)=333 f^{0.54}$, [34]; Line 8: Kanto, Japan, $Q(f)=32 f^{0.95}$ [11]; Line 9: South Eastern Korea, $Q(f)=$ $111 f^{1.05}$ [35]; (b) Comparison of $Q(f)$ for S-waves of the NW Himalaya region obtained in this study (solid line, $Q(f)=127 f$ ${ }^{0.96}$ ) with those of other regions of the world (dashed lines) and India (solid lines). Line 1: Chamoli, Himalaya, $Q(f)=87 f^{0.71}$, [30]; Line 2: Kachchh region, Gujarat, $Q(f)=74 f^{1.06}$, [31]; Line 3: Koyna region, $Q(f)=71 f^{1.32}$, [32]; Line 4: Mainland region, Gujarat, $Q(f)=118 f^{0.65}$, [31]; Line 5: Saurastra region, Gujarat, $Q(f)=149 f^{1.43}$, [31]; Line 6: Baltic Shield, $Q(f)=125 f$ 1.08, [33]; Line 7: Central South Korea, $Q(f)=333 f^{0.42}$, [34]; Line 8: Kanto, Japan, $Q(f)=83 f^{0.73}$, [11]; Line 9: South Eastern Korea, $Q(f)=250 f^{1.08}$, [35].

Korea. However, they differ in absolute values from the regions like Koyna, Chamoli, Kanto region of Japan and Central South Korea. The ratio $Q_{S} / Q_{P}$ is found to be greater than one in the present analysis, which is in agree- ment with the laboratory measurements and other studies reported in the literature. This also indicates that scattering is an important factor contributing to the attenuation of body waves in the region. A comparison of $Q_{C}$ ob- 
tained by [1] and $Q_{\mathrm{S}}$ obtained in the present study show that $Q_{\mathrm{S}}<Q_{\mathrm{C}}$ for all the frequency ranges reflecting the enrichment of coda waves which suggests the importance of scattering attenuation to the attenuation of $\mathrm{S}$ waves in the region. The attenuation parameters obtained in this study are useful for the estimation of source parameters and simulation of earthquake ground motions in the region which is needed to assess the seismic hazard in the region of NW Himalaya, India.

\section{Acknowledgements}

The authors are thankful to Naresh Kumar and H. S. Virk for providing the micro-earthquake data. We are also thankful to SIC, C-MMACS for his permission and to provide the facilities to complete this work. We also thank the Department of Science and Technology, Government of India to provide the fellowship to Preeti under DST project R-0-156.

\section{REFERENCES}

[1] N. Kumar, I. A. Parvez and H. S. Virk, "Estimation of Coda Wave Attenuation for NW Himalayan Region Using Local Earthquakes," Physics of the Earth and Planetary Interiors, Vol. 151, No. 3-4, 2005, pp. 243-258. doi:10.1016/j.pepi.2005.03.010

[2] H. Sato, "Thermal Structure of the Mantle Wedge beneath Northeastern Japan: Magmatism in an Island Arc from the Combined Data of Seismic Anelasticity and Velocity and Heat Flow," Journal of Volcanology and Geothermal Research, Vol. 51, No. 3, 1992, pp. 237-252. doi:10.1016/0377-0273(92)90125-W

[3] K. Aki, "Attenuation of Shear Waves in the Lithosphere for Frequencies from 0.05 to $2 \mathrm{~Hz}$," Physics of the Earth and Planetary Interiors, Vol. 21, 1980, pp. 50-60. doi:10.1016/0031-9201(80)90019-9

[4] L. Knopoff, "Q," Reviews of Geophysics, Vol. 2, No. 4, 1964, pp. 625-660. doi:10.1029/RG002i004p00625

[5] B. J. Mitchell, "Regional Variation and Frequency Dependence of $\mathrm{Q}_{\mathrm{NL}}$ in the Crust of the United States," Bulletin of the Seismological Society of America, Vol. 71, 1981, pp. 1531-1538.

[6] K. Aki, "Analysis of Seismic Coda of Local Earthquakes as Scattered Waves," Journal of Geophysical Research, Vol. 74, No. 2, 1969, pp. 615-631. doi:10.1029/JB074i002p00615

[7] K. Aki and B. Chouet, "Origin of the Coda Waves: Source Attenuation and Scattering Effects," Journal of Geophysical Research, Vol. 80, No. 23, 1975, pp. 3322-3342. doi:10.1029/JB080i023p03322

[8] R. Hermann, "Q Estimates Using Coda of Local Earthquakes," Bulletin of the Seismological Society of America, Vol. 70, No. 2, 1980, pp. 447-468.

[9] B. J. Mitchell, "Anelastic Structure and Evolution of the Continental Crust and Upper Mantle from Seismic Surface Wave Attenuation," Reviews of Geophysics, Vol. 33, No. 4, 1995, pp. 441-462. doi:10.1029/95RG02074
[10] T. G. Rautian, V. I. Khalturin, V. G. Martynov and P. Molnar, "Preliminary Analysis of the Spectral Content of $\mathrm{P}$ and S-Waves from Local Earthquakes in the Garm, Tadjikista Region," Bulletin of the Seismological Society of America, Vol. 68, 1978, pp. 949-971.

[11] K. Yoshimoto, H. Sato and M. Ohtake, "Frequency Dependent Attenuation of $\mathrm{P}$ and S-Waves in the Kanto Area, Japan, Based on the Coda Normalization Method," Geophysical Journal International, Vol. 114, No. 1, 1993, pp. 165-174. doi:10.1111/j.1365-246X.1993.tb01476.x

[12] S. W. Roecker, B. Tucker, J. King and D. Hatzfeld, "Estimates of Q in Central Asia as a Function of Frequency and Depth Using the Coda of Locally Recorded Earthquakes," Bulletin of the Seismological Society of America, Vol. 72, No. 1, 1982, pp. 129-149.

[13] J. J. Pulli, "Attenuation in New England," Bulletin of the Seismological Society of America, Vol. 74, No. 4, 1984, pp. 1149-1166.

[14] S. Rhea, "Q Determined from Local Earthquakes in South Carolina Coastal Plain," Bulletin of the Seismological Society of America, Vol. 74, No. 6, 1984, pp. 2257-2268.

[15] J. M. Ibanez, E. Del Pezzo, F. De Miguel, M. Herraiz, G. Alguacil and J. Morales, "Depth Dependent Seismic Attenuation in the Granada Zone (Southern Spain)," Bulletin of the Seismological Society of America, Vol. 80, No. 5, 1990, pp. 1222-1234.

[16] A. Akinci, A. G. Taktak and S. Ergintav, "Attenuation of Coda Waves in Western Anatolia," Physics of the Earth and Planetary Interiors, Vol. 87, No. 1-2, 1994, pp. 155165. doi:10.1016/0031-9201(94)90028-0

[17] S. C. Gupta, V. N. Singh and A. Kumar, "Attenuation of Coda Waves in the Garhwal Himalaya, India," Physics of the Earth and Planetary Interiors, Vol. 87, No. 3-4, 1995, pp. 247-253. doi:10.1016/0031-9201(94)02968-H

[18] J. Ni and M. Barazangi, "Seismotectonics of the Himalayan Collision Zone: Geometry of the Underthrusting Indian Plate beneath the Himalayas," Journal of Geophysical Research, Vol. 89, No. B2, 1984, pp. 1147-1163. doi:10.1029/JB089iB02p01147

[19] P. Molnar, "A Review of the Seismicity and the Rates of Active under Thrusting and Deformation at the Himalaya," Journal of Himalayan Geology, Vol. 1, No. 2, 1990, pp. 131-154.

[20] P. Molnar, B. E. Tucker and J. N. Brune, "Corner Frequencies of P- and S-Waves and Models of Earthquake Sources," Bulletin of the Seismological Society of America, Vol. 63, No. 6, 1973, pp. 2091-2104.

[21] Y. Zeng, F. Su and K. Aki, "Scattered Wave Energy Propagation in a Random Isotropic Scattering Medium, I. Theory," Journal of Geophysical Research, Vol. 96, No. B1, 1991, pp. 607-619. doi:10.1029/90JB02012

[22] A. Frankel, "Mechanisms of Seismic Attenuation in the Crust: Scattering and Anelasticity in New York State, South Africa, and Southern California," Journal of Geophysical Research, Vol. 96, 1991, pp. 6269-6289. doi:10.1029/91JB00192

[23] G. Sarkar and A. Abers, "Comparison of Seismic Body Wave and Coda Wave Measures of Q," Pure and Applied 
Geophysics, Vol. 153, No. 2-4, 1998, pp. 665-683. doi:10.1007/s000240050213

[24] M. Hoshiba, "Simulation of Multiple Scattered Coda Wave Excitation Based on the Energy Conservation Law," Physics of the Earth and Planetary Interior, Vol. 67, No. 1-2, 1991, pp. 123-136. doi:10.1016/0031-9201(91)90066-Q

[25] M. N. Toksoz, A. H. Johnston and A. Timur, "Attenuation of Seismic Waves in Dry and Saturated Rocks-I Laboratory Measurements," Geophysics, Vol. 44, No. 1, 1979, pp. 681-690. doi:10.1190/1.1440969

[26] S. Mochizuki, "Attenuation in Partially Saturated Rocks," Journal of Geophysical Research, Vol. 87, No. B10, 1982, pp. 8598-8604. doi:10.1029/JB087iB10p08598

[27] K. W. Winkler and A. Nur, "Seismic Attenuation Effects of Pore Fluids and Frictional Sliding," Geophysics, Vol. 47, No. 1, 1982, pp. 1-15. doi:10.1190/1.1441276

[28] M. Vassiliou, C. A. Salvado and B. R. Tittmann, "Seismic Attenuation," In: R. S. Carmichael, Ed., CRC Handbook of Physical Properties of Rocks, Vol. 3, CRC Press, Boca Raton, 1982.

[29] D. H. Johnston, M. N. Toksoz and A. Timur, "Attenuation of Seismic Waves in Dry and Saturated Rocks: I," Mechanics in Geophysics, Vol. 44, 1979, pp. 691-711. doi:10.1190/1.1440970
[30] B. Sharma, S. S. Teotia, D. Kumar and P. S. Raju, "Attenuation of $\mathrm{P}$ and S-Waves in the Chamoli Region, Himalaya, India," Pure and Applied Geophysics, Vol. 166, No. 12, 2009, pp. 1949-1966. doi:10.1007/s00024-009-0527-9

[31] S. Chopra, B. K. Rastogi and D. Kumar, "Attenuation of High Frequency P- and S-Waves in the Gujarat Region, India," Pure and Applied Geophysics, Vol. 168, No. 5, 2010, pp. 797-781. doi:10.1007/s00024-010-0143-8

[32] B. Sharma, S. S. Teotia and D. Kumar, "Attenuation of P, S and Coda-Waves in Koyna Region, India," Journal of Seismology, Vol. 11, No. 3, 2007, pp. 327-344. doi:10.1007/s10950-007-9057-Z

[33] L. B. Kvamme and J. Havskov, "Q in Southern Norway," Bulletin of the Seismological Society of America, Vol. 79, No. 5, 1989, pp. 1575-1588.

[34] K. D. Kim, T. W. Chung and J. B. Kyung, "Attenuation of High Frequency P- and S-Waves in the Crust of Choongchung Provinces, Central South Korea," Bulletin of the Seismological Society of America, Vol. 94, No. 3, 2004, pp. 1070-1078. doi:10.1785/0120030137

[35] T. W. Chung and H. Sato, "Attenuation of High Frequency P- and S-Waves in the Crust of Southeastern South Korea," Bulletin of the Seismological Society of America, Vol. 91, 2001, pp. 1867-1874. doi:10.1785/0120000268 